\title{
CORRECTION
}

Morteza Nekouei · Mehdi Raghebi · Meisam Mohammadi

\section{Correction to: Free vibration analysis of laminated composite conical shells reinforced with shape memory alloy fibers}

Published online: 17 September 2019

(C) Springer-Verlag GmbH Austria, part of Springer Nature 2019

\section{Correction to: Acta Mech \\ https://doi.org/10.1007/s00707-019-02501-z}

The article, "Free vibration analysis of laminated composite conical shells reinforced with shape memory alloy fibers", written by Mehdi Raghebi was originally published electronically on the publisher's internet portal (currently SpringerLink) on 24 August 2019 with open access. With the author(s)' decision to step back from Open Choice, the copyright of the article changed on September 2019 to $\odot$ Springer-Verlag GmbH Austria, part of Springer Nature 2019, and the article is forthwith distributed under the terms of copyright.

The original article was corrected.

Publisher's Note Springer Nature remains neutral with regard to jurisdictional claims in published maps and institutional affiliations.

The original article can be found online at https://doi.org/10.1007/s00707-019-02501-z.

M. Nekouei · M. Raghebi (凶)

Department of Mechanical Engineering, University of Birjand, Birjand, Iran

E-mail: raghebi@birjand.ac.ir

Tel.: +985632202049

Fax: +98 5632202036

M. Mohammadi

Department of Mechanical Engineering, Vali-e-Asr University of Rafsanjan, Rafsanjan, Iran 